\title{
FRENECTOMY: A CASE REPORT
}

\author{
Dr. Shakir Hussain Rather ${ }^{1}$ \\ ${ }^{1,}$ Department of Pedodontic and Preventive Dentistry KDC, Meerut. \\ Dr. Neeraj Kant Panwar ${ }^{2}$ \\ ${ }^{2}$ Department of Pedodontic and Preventive Dentistry KDC, Meerut. \\ Dr. N. Nisanth ${ }^{3}$ \\ ${ }^{3}$ Private Practitioner
}

Article DOI: $\underline{\text { https://doi.org/10.36713/epra4402 }}$

*Corresponding Author: Dr. Shakir Hussain Rather

\begin{abstract}
High frenum attachment is a very common problem in the population and causes various problems in function and aesthetics. It is managed by procedures such as frenotomy and frenectomy. Aberrant frenum can be removed by any of the modification techniques that have been proposed, a functional and an aesthetic outcome can be achieved by a proper technique selection, based on the type of the frenal attachment.
\end{abstract}

KEYWORDS: Labial frenectomy, midline diastema.

\section{INTRODUCTION}

The presence of an aberrant frenum being one of the aetiological factors for the persistence of a midline diastema, the focus on the frenum has become essential [1]. A frenum attaches the lip and cheek to the alveolar mucosa, the gingiva and the underlying periosteum and the high frenum attachment may cause gingival recession when they are attached too close to the gingival margin.

Placek et $a^{[2]}$ have classified frenum depending on the extension of attachment of fibers,

(1) Mucosal: when the frenal fibers are attached up to mucogingival junction,

(2) Gingival: when fibers are inserted within attached gingiva,

(3) Papillary: when fibers are extending into interdental papilla,
(4) Papilla penetrating: when the frenal fibers cross the alveolar process and extend up to palatine papilla.

The maxillary labial frenum develops as a posteruptive remnant of the ectolabial bands which connect the tubercle of the upper lip to the palatine papilla. When the central incisors erupt widely separated, no bone is deposited inferior to the frenum. A V-shaped bony cleft between the two central incisors and an abnormal frenum attachment results.

\section{CASE REPORT}

A 14 year old male patient reported in the Department of Pedodontics \& Preventive Dentistry K.D.C Meerut. On intraoral examination, high frenal attachment \& midline diastema $(3 \mathrm{~mm})$ were observed. After detailed explanation of procedure, patient was advised 
frenectomy and written consent was obtained from the patient.

\section{Procedure: Labial Frenectomy (V-Y Plasty} used in this case)

After the area was anaesthetized with a local infiltration. The frenum was held with the haemostat and an incision was made in the form of $\mathrm{V}$ on the undersurface of the frenal attachment. The frenum was then relocated at an apical position and the $\mathrm{V}$ shaped incision was converted into a $\mathrm{Y}$, while it was sutured with 4-0 silk sutures and periodontal pack was placed as shown in figures 1-5. The patient was given instructions to avoid taking hot and spicy food for a few days and to maintain oral hygiene. Postoperative analgesics were given to the patient. After 2 weeks of follow-up, significant healing was noted and after 1 month, complete healing of the surgical area with normal frenal attachment was reported.

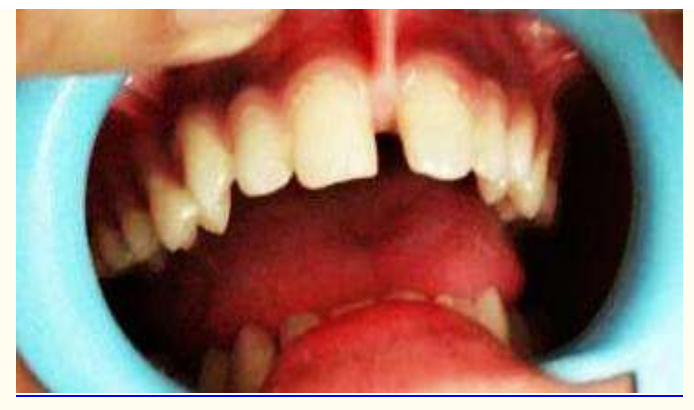

[Fig 1] Pre-operative

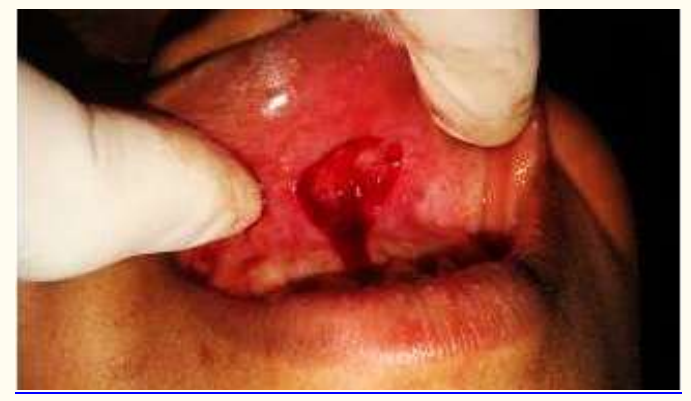

[Fig 2] Frenum excised

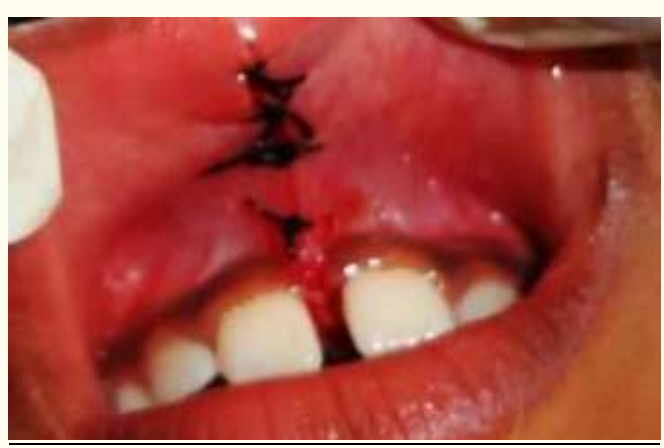

[Fig 3] Sutures placed 


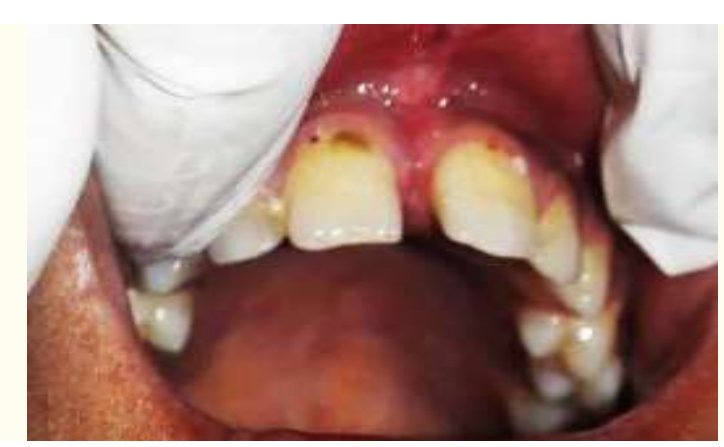

[Fig 4] One-month postoperative picture

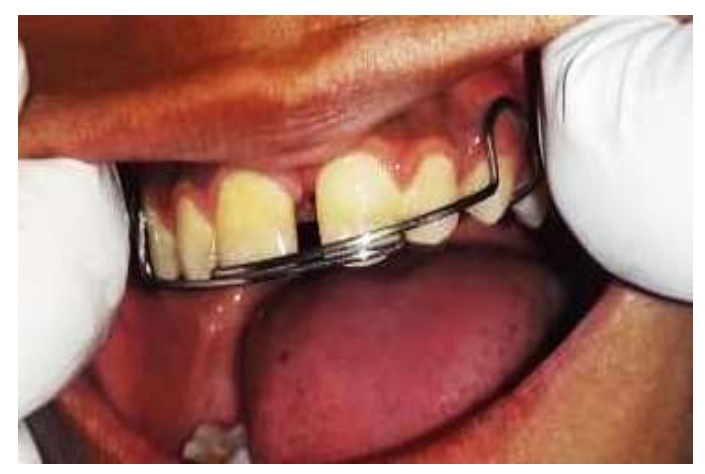

[Fig 5] Split labial bow

\section{DISCUSSION}

Aesthetic concerns have led to an increasing importance in seeking dental treatment. Aberrant frenum being one of the aetiological factors for the persistence of a midline diastema, the focus on the frenum has become essential. The high frenal attachment leads to gingival recession when they are attached too closely to the gingival margin. Archer's classical frenectomy technique is an extensive procedure which causes scarring and loss of interdental papilla[3,4]. Conservative approaches like Edward's frenectomy, frenum relocation by Z-plasty and free gingival graft [5]. A number of modifications have been developed to solve the problem caused by an abnormal labial frenum. But in most of the techniques the zone of attached gingiva and aesthetics are not considered, surgical frenectomy techniques like conventional (classical) technique[ ${ }^{6]}$. Miller's technique using unilateral pedicle flap and frenectomy technique using bilateral pedicle flap and results are reported[7,8,9]. The frenectomy technique using pedicle flap gives good aesthetic results, colour match, gain in attached gingiva and no anaesthetic scar formation as healing takes place by primary intention. The Z-plasty technique was found to be ideal for a broad, thick hypertrophic frenum with a low insertion, which was associated with an interincisor diastema and a short vestibule. It achieved both the removal of the fibrous band and the vertical lengthening of the vestibule [10]. Among all the approaches for frenectomy which were employed in the present case series, the electrocautery procedure offered the advantage of minimal time consumption and a bloodless field during the surgical procedure, with no requirement of sutures[11].

\section{CONCLUSION}

High frenum attachment is a very common problem in the population. in addition to that high frenum also hinders oral hygiene maintenance. It is managed by procedures such as frenotomy and frenectomy. While an aberrant frenum can be removed by any of the modification techniques that have been proposed, a functional and an aesthetic outcome can be achieved by a proper technique selection, based on the type of the frenal attachment. Though the approaches to the problem of not using the traditional scalpel, like electro surgery and lasers have merits, further improvements can still be attempted. 


\section{REFERENCES}

1. Devishree, Sheela $K G$ and Shubhashini $P V$. Journal of Clinical and Diagnostic Research. 2012 November, Vol-6(9): 1587-1592.

2. Placek M, Miroslav S, Mrklas L. Significance of the labial frenal attachment in periodontal disease in man. Part 1; Classification and epidemiology of the labial frenum attachment. J Periodontol 1974;45:891-4.

3. Hungund et al., Dentistry 2013, 4:1, Journal of Clinical and Diagnostic Research. 2012 November, Vol-6(9): 1587-1592

4. Puig JR, Lefebvre E, Landat F. The Z-plasty technic which was applied tohypertrophy of the upper labial frenum. Rev Stomatol Chir Maxillofac 1977;78:351-6.

5. Langdon JD, Patel MF. Reconstructive surgery orofacial flaps and skin grafting. In: Operative Maxillofacial Surgery. Chapman and Hall, London; 1998; 73.

6. Kruger GO. Acquired defects of the hard and soft tissues of the face. In: Gustav O Kruger (ed) Oral and maxillofacial surgery. St.Louis: Mosby, 48788.

7. Miller PD. Regenerative and reconstructive periodontal plastic surgery. In: Mucogingival surgery. Dental Clinics of North America. 1988;32:287-306.

8. Miller PD. Reconstructive periodontal plastic surgery (mucogingival surgery). $J$ Tennessee Dental Association 1991;71:14

9. Miller PD, Allen EP. The development of periodontal plastic surgery Periodontology

10. Huang WJ, Creath CJ. The midline diastema: a review on its etiology and treatment. Pediatric Dentistry. 1995;17:171-9.

11. Jhaveri H. Jhaveri Hiral., editor. The Aberrant Frenum. Dr. PD Miller the father of periodontal plastic surgery. 2006:29-34. 